\title{
Effect of Two Fungicides on Mycelial Growth of Fungi \\ Causing Leaf Blight and Wilt of the Rubber Plant (Hevea brasiliensis Muell Arg.) in Cameroon
}

\author{
Ntsomboh-Ntsefong Godswill \\ Department of Plant Biology, Faculty of Science, University of Yaounde 1, P. O. Box 812 \\ Yaounde, Cameroon \& Department of Research Valorisation and Innovation, Institute of \\ Agricultural Research for Development (IRAD), Cameroon. Telephone: +237 679941910 \\ E-mail: ntsomboh@yahoo.fr
}

\begin{abstract}
Ngoueko Tefonou Bernadette-Sorele
Faculty of Agronomy and Agricultural Sciences (FASA), University of Dschang, Cameroon. P. O. Box 222 FASA, University of Dschang, Cameroon. Telephone: +237 670809276 E-mail: tefonous@gmail.com

Dzokouo Dzoyem Camille Ulrich

Institute of Agricultural Research for Development (IRAD), Njombe, Cameroon. P.

O. Box 13 Njombe, Cameroon. Telephone: +237 694777733

E-mail: camille.dzoyem@yahoo.fr
\end{abstract}

\begin{abstract}
Yaouba Aoudou
Faculty of Agronomy and Agricultural Sciences (FASA), University of Dschang, Cameroon. P. O. Box 222 FASA, University of Dschang, Cameroon. Telephone: +237 695409547 E-mail: yaoubaaoudou@yahoo.fr
\end{abstract}

Nyaka Ngobisa Aurelie Irene Claire (Corresponding Author)

Institute of Agricultural Research for Development (IRAD), Njombe, Cameroon. P.

O. Box 13 Njombe, Cameroon. Telephone: +237 691846161 E-mail: boulnyaka@yahoo.com

Received: May 6, 2020

doi:10.5296/jas.v8i4.17476
Accepted: July 27, 2020 Published: August 4, 2020

URL: https://doi.org/10.5296/jas.v8i4.17476 


\section{Abstract}

Rubber (Hevea brasiliensis Muell. Arg., Euphorbiaceae) is a tropical tree crop mainly grown for the industrial production of latex. The rubber sector in Cameroon is faced with the effects of global economic crisis and a drop in the yield of latex due to several pests and diseases. This study focused on leaf diseases caused by Fusarium oxysporum and Pestalotiopsis microspora. The fungi were isolated from the leaves of the rubber plant and cultured for characterization on two media (Potato Dextrose Agar (PDA) and Potato Carrot Dextrose Agar (PCDA)) at various temperature and $\mathrm{pH}$ levels. Using the poison food technique, an in vitro assay was done to assess the effect of two fungicides (Synthetic Fungicide 1 (SF1) and Synthetic Fungicide 2 (SF2)) at the respective doses of $0.006,0.013$ and 0.025 g.L , $^{-1}$ and $0.005,0.01$ and $0.02 \mathrm{~g} . \mathrm{L}^{-1}$ on the growth of the two fungi. Results obtained show that PDA is most favourable for the growth of both fungi compared to PCDA. Both fungi attained optimal growth at $\mathrm{pH} 7$ and at an incubation temperature of $25^{\circ} \mathrm{C}$. Neither $F$. oxysporum nor $P$. microspora grew on SF1-amended PDA and PCDA at all doses of the fungicide. SF2 significantly $(\mathrm{P}>0.05)$ inhibited the growth of $P$. microspora by $53.3 \%$ at the dose of 0.025 g. $\mathrm{L}^{-1}$ while $F$. oxysporum was less sensitive to the fungicide at all doses. In vitro pathogenicity test revealed similar disease symptoms as those observed in the field. This study shows that SF1 is the best fungicide against $F$. oxysporum and $P$. microspora as it gave $100 \%$ inhibition on the growth of both fungi.

Keywords: Rubber, Fusarium oxysporum, Pestalotiopsis microspora, mycelial growth synthetic fungicides

\section{Introduction}

Rubber (Hevea brasiliensis (Willd. ex Adr. de Juss.) Muell. Arg.) is a tropical tree crop belonging to the family of Euphorbiaceae (Martins and Zieri, 2003). It is mainly grown for the industrial production of latex, a milky plant liquid, which serves as a basis for various rubber products (Verheye, 2010). Natural rubber has been an important commodity for the past 100 years. It is synthesized by over 2000 plant species belonging to 300 different genera (Gazis and Chaverri, 2010). Currently, Hevea brasiliensis has been the only resource for commercial natural rubber production (Venkatachalam et al., 2013), with about $90 \%$ of the total world production (Verheye, 2010) and $40 \%$ of the total world's consumption (Gazis and Chaverri, 2010).

Cameroon's economy is one of the most diversified in sub-Saharan Africa. It is a producer and exporter of rubber as well as cocoa, coffee, cotton, timber among others. The production of rubber was observed to increase slightly after 1988 (Amin, 2002). However, its productivity is compromised by the incidence of some economically important fungal diseases (Nyaka et al., 2018). Most of rubber tree diseases are caused by fungi and some of the diseases can lead to serious damages in the rubber plantation (Safwan et al., 2019). One of such rubber diseases is leaf blight caused by Pestalotiopsis microspora (Nyaka et al., 2018). Leaf diseases of rubber can cause severe defoliation, ranging from 50 to $100 \%$, with a consequent reduction in yield (UIA, 2000). The drop observed could also be as a result of poor agricultural practices, the cultivation of non-resistant rubber clones as well as the 
occurrence of various pests and diseases that affect the normal physiological processes of the plant, thereby reducing the yield obtained. Even the use of modern systemic fungicides associated with greatly improved application techniques have failed to prevent high losses (Reinhard, 2007). Effective management of these diseases is very important to boost productivity and increase yields of the plantations (Safwan et al., 2019).

The objectives of the present study were to assess the morphological characteristics of two disease-causing fungi (Fusarium oxysporum and Pestalotiopsis microspora) from the leaves of Hevea brasiliensis, and to test the effect of two synthetic fungicides (SF1 and SF2) on their mycelial growth. To achieve these objectives, fungi were isolated from the leaves of the rubber plants, and their growth on two culture media was evaluated at various incubation temperatures and $\mathrm{pH}$ levels. In vitro pathogenicity test of these fungi on detached leaves of the rubber plant was also done.

\section{Materials and Methods}

\subsection{Pathogen Isolation and Purification}

Various leaf symptoms (Fig. 1) were initially observed on rubber plants in the field. In order to identify the causal agents of blight and wilt, isolates were obtained from diseased leaves of rubber trees showing typical symptoms of blight and wilt from three different clones (GT20, GT1 and PB235) at the bud-wood nursery of the IRAD Ekona experimental farm in April 2017. Leaf samples were collected, placed in bags and transported to the rubber pathology laboratory in Ekona where they were processed the following day for fungal isolation. Pieces of leaf tissue, $\sim 9 \mathrm{~mm}^{2}$, were cut from the edges of blight or wilt lesions, surface-disinfected by immersion in $0.1 \%$ sodium hypochlorite $(\mathrm{NaOCl})$ for $1 \mathrm{~min}$, rinsed three times with sterile distilled water and inoculated onto Potato Dextrose Agar (PDA) and Potato Carrot Dextrose Agar (PCDA) plates. The plates were incubated at $25{ }^{\circ} \mathrm{C}$, under continuous and constant fluorescent light according to the protocol in Sanjay (2004). The putative pathogens were isolated as single hyphae emerging from the disinfected leaf tissue. Isolates were further purified by sub culturing from single conidia or hyphal tips and preserved at $25{ }^{\circ} \mathrm{C}$. Sub-culturing was done repeatedly until pure cultures were obtained. Five pure sample cultures were finally obtained and were labelled IC, IID, IIE, IIIC and P.

\subsubsection{Microscopy}

Each fungal colony was mounted under a light microscope (AC 220V) for identification. For this, samples of the mycelium were collected and placed on a slide. A drop of water was added and then covered with a slide cover. The slide was then mounted on the microscope and the phenotypic features of each observed. Features observed included the presence or absence of septa and/or nuclei on the hyphae, the presence of spores, colour and shape of spores, and the position of spores on the hyphae. Methylene blue was equally used on the slides and this enabled the spores to be seen clearly under the microscope. Samples were observed at various magnifications, beginning from the smallest; 40x, through 100x to 400x where the features could be clearly seen. Images obtained were compared with those found in literature. 


\subsubsection{Determination of the Best Culture Medium for Fungal Growth}

Petri dishes were plated with PDA (Potato Dextrose Agar) and PCDA (Potato Carrot Dextrose Agar) culture media. PCDA medium was prepared in the same way as PDA but with the addition of $20 \mathrm{~g}$ of carrot in order to make the medium less rich in starch. A $10 \mathrm{~mm}$ diameter cork borer was flame sterilized and used to collect mycelial discs from the different clones. Each Petri dish received a mycelial disc at its center; dishes were sealed, labeled and placed on a slab at ambient temperature of $25 \pm 2^{\circ} \mathrm{C}$. Each fungal sample was replicated three times. Measurement of radial growth of mycelium began on the third day after sub-culture. Data was collected daily and at the same time by drawing two perpendicular lines at the center of the fungal disc and by marking vertical lines at the edge of the mycelial growth on each side. Using a ruler, the diameter was measured in both directions while subtracting that of the cork borer $(10 \mathrm{~mm})$ at each time. The average of each was obtained, and the following formula was used to determine the fungal growth:

$$
\mathrm{R}=\frac{\mathrm{D} 1+\mathrm{D} 2}{2}-\mathrm{Do}_{0}
$$

Where $\mathrm{R}=$ radial growth

D1 and D2= diameters measured in both directions

$\mathrm{D} 0=$ diameter of cork borer

\subsection{Determination of Daily Growth Rate}

It was calculated using the formula proposed by Djeugap (2013). It is stated as follows:

$$
\mathrm{V}=[(\mathrm{DMj} 1-\mathrm{DMj} 0)+(\mathrm{DMj} 2-\mathrm{DMj} 1)+\ldots+(\mathrm{DMjn}-\mathrm{DMjn}-1)] / \mathrm{n}
$$

Where $\mathrm{V}=$ daily average radial growth

$\mathrm{DMjn}=$ average diameter on the $\mathrm{n}^{\text {th }}$ day $($ given by $\mathrm{DMjn}=(\mathrm{d} 1+\mathrm{d} 2) / 2$

$\mathrm{DMj} 0=$ internal diameter of cork borer $(10 \mathrm{~mm})$

$\mathrm{n}=$ number of days required to fill Petri dish

\subsubsection{Determination of the Best $\mathrm{pH}$ for Fungal Growth}

PDA and PCDA were prepared and placed in $250 \mathrm{ml}$ conical flasks. The various $\mathrm{pH}$ required were 5, 7 and 9. The $\mathrm{pH}$ meter (USAID) was calibrated with the help of a $\mathrm{pH}$ Buffer Powder ( $\mathrm{pH} 4.01$ at $25{ }^{\circ} \mathrm{C}$ ). The initial $\mathrm{pH}$ of the medium was measured and thereafter adjusted to the required $\mathrm{pH}$ levels by the use of a concentrated acid (nitric acid) to reduce the $\mathrm{pH}$, and a strong base $(\mathrm{NaOH})$ to increase the $\mathrm{pH}$ till achievement of the necessary $\mathrm{pH}$. A magnetic agitator (Fisherbrand 10517) was connected to the $\mathrm{pH}$ meter and had as role to stir and homogenize the medium. The flasks were labeled accordingly, corked and placed in an autoclave for sterilization at the temperature of $121^{\circ} \mathrm{C}$ and pressure of 1 bar for 15 minutes. The flasks were removed, placed on a slab to cool and then under a sterile hood the media were poured into $70 \mathrm{~mm}$ sterile Petri dishes and allowed to solidify. Each Petri dish then 
received a mycelial disc of the various fungal cultures at its center, collected by the use of a $10 \mathrm{~mm}$ flame-sterilized cork borer. Petri dishes were sealed and placed on a slab at ambient temperature of $25 \pm 2{ }^{\circ} \mathrm{C}$ for 10 days, time needed for the fungal cultures to totally fill the Petri dishes. Fungal diameter was measured every 24 hours to assess the growth rate of the fungi at the various $\mathrm{pH}$ levels.

\subsection{Determination of the Best Temperature for Fungal Growth on PDA}

PDA was prepared and sterilized in the autoclave. It was allowed to cool, supplemented with $250 \mathrm{mg}$ of streptomycin sulphate and $20 \mathrm{ml}$ were poured into $70 \mathrm{~mm}$ sterile Petri dishes under a sterile hood. After the medium had solidified, a $10 \mathrm{~mm}$ flame-sterilized cork borer was used to collect mycelial discs of the various fungal cultures which were then placed at the center of each Petri dish. These were then placed in an incubator (Memmert 854 schwabach, $220 \mathrm{~V}$ ) at the various temperatures, namely $25^{\circ} \mathrm{C}, 30^{\circ} \mathrm{C}$ and $35^{\circ} \mathrm{C}$ for 12 days, time required for the fungi to fill the Petri dishes. Data on the radial growth was collected daily (every 24 hours) as from day 1 after inoculation, in order to assess the growth rate at the various temperatures.

\subsection{Pathogenicity Test}

This was done in vitro using detached leaves. Spore production was initiated by scraping the fungal mycelia with a sterile surgical knife under a laminar flow hood. Sterile distilled water was then poured on the surface, swirled and allowed under alternate light and dark conditions. This was repeated for three days.

Young (10-day-old) and apparently healthy leaves of the GT1 clone were collected from the seed nursery at the IRAD Ekona experimental farm. Detached leaves were taken to the laboratory, washed with tap water, dipped into 5\% sodium hypochlorite solution and then into $95 \%$ alcohol. They were finally rinsed thoroughly with sterile distilled water to remove traces of disinfectant.

$10 \mathrm{ml}$ of distilled water (source of humidity) were poured into sterile Petri dishes and the detached leaves were placed in the dishes. With the help of a sterile syringe, the spore suspension was collected and six drops placed on the surface of the leaves. The inoculated leaves were then placed on a slab at ambient temperature of $25 \pm 2{ }^{\circ} \mathrm{C}$ and observed for the appearance of disease symptoms.

\subsection{Application of Fungicides}

Two fungicides were evaluated in vitro against the fungi following the poison food technique (Dhingra and Sinclair, 1985). PDA was prepared in $250 \mathrm{ml}$ conical flasks and autoclaved at the temperature of $121{ }^{\circ} \mathrm{C}$ and pressure of 1 bar for 15 minutes. Commercially formulated fungicides were then dissolved in a small amount of alcohol and added into the sterile PDA at various doses. Three doses were used for each fungicide: 0.005 g.L $\mathrm{L}^{-1}, 0.01$ g.L $\mathrm{L}^{-1}$ and 0.02 g.L $\mathrm{L}^{-1}$ for SF1, and 0.006 g.L $\mathrm{L}^{-1}, 0.013$ g.L $\mathrm{L}^{-1}$ and 0.025 g.L $\mathrm{L}^{-1}$ for SF2. $20 \mathrm{ml}$ of the PDA mixed with the fungicides was poured into $70 \mathrm{~mm}$ Petri dishes. After solidification, the inoculum (10 $\mathrm{mm}$ disc) from seven-day-old cultures of the test organisms was placed at the center of each plate and placed on a slab at ambient temperature of $25 \pm 2{ }^{\circ} \mathrm{C}$. Each treatment was 


\section{Macrothink Institute ${ }^{T M}$}

replicated three times with three Petri dishes per replication. Radial growth was measured from day one till the day when the control filled up the Petri dishes.

Table 1. Information on fungicides used in the experiment

Code Mode of action Trade name Concentration (g.L L $^{-1}$ )

Synthetic fungicide $1(\mathrm{SF}) \quad$ Systemic $\quad$ Benlate 50 WP $\quad 0.005,0.01,0.02$

Synthetic Fungicide 2 (SF2) Contact Pencozeb 80 WP $\quad 0.006,0.013,0.025$

Information on the fungicides used in the experiment is listed in Table 1.

\subsection{Calculation of Percent Inhibition}

Percent inhibition of growth was calculated using the following formula (Naz et al., 2006).

$$
\text { Percent inhibition, } I=\frac{X-Y}{X} \times 100
$$

Where $\mathrm{X}=$ Average radial growth in control Petri dish

$\mathrm{Y}=$ Average radial growth in treated Petri dish

\subsection{Experimental Design and Data Analysis}

The experimental design used was the completely randomized design with three (03) treatments and four (04) replications. Data were keyed in and treated using Microsoft Excel 2013 and Analysis of Variance (ANOVA) was done using the STATBOX Statistical Package, 6.40 version. Means were compared using Tukey Tests. Newman and Keuls Tests were used to separate means at significance level of $5 \%$.

\section{Results and Discussion}

\subsection{Isolation and Purification}

Various leaf symptoms initially observed on rubber plants in the field are shown in Figure 1.
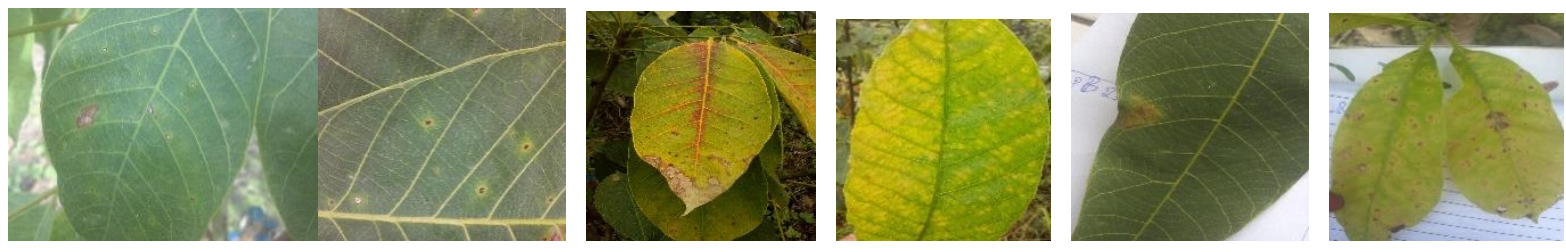

Figure 1. Some disease symptoms on rubber leaves at the IRAD Ekona budwood nursery

The figures (2 to 4 ) show the appearance of the fungal mycelia in Petri dishes, and that of the hyphae and spores under the microscope. 

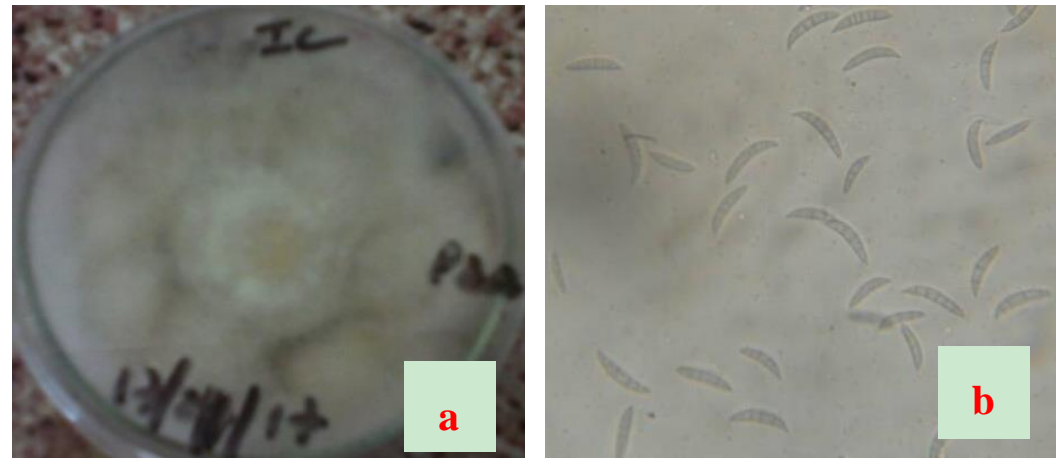

Figure 2. Morphology of sample I identified as Fusarium oxysporum: (a) Pure culture, (b) Hyphae
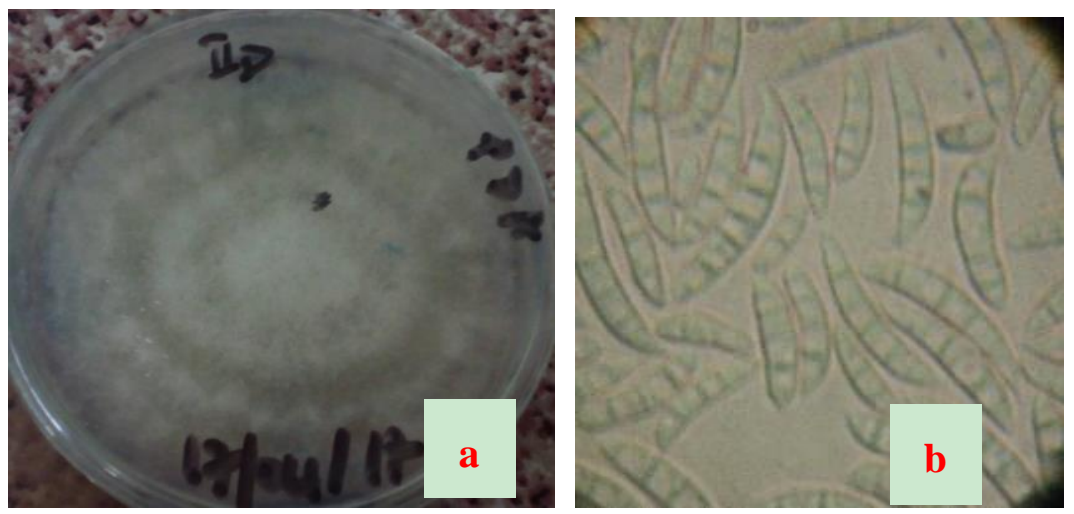

Figure 3. Morphology of sample II identified as Fusarium oxysporum: (a) Pure culture, (b) Hyphae
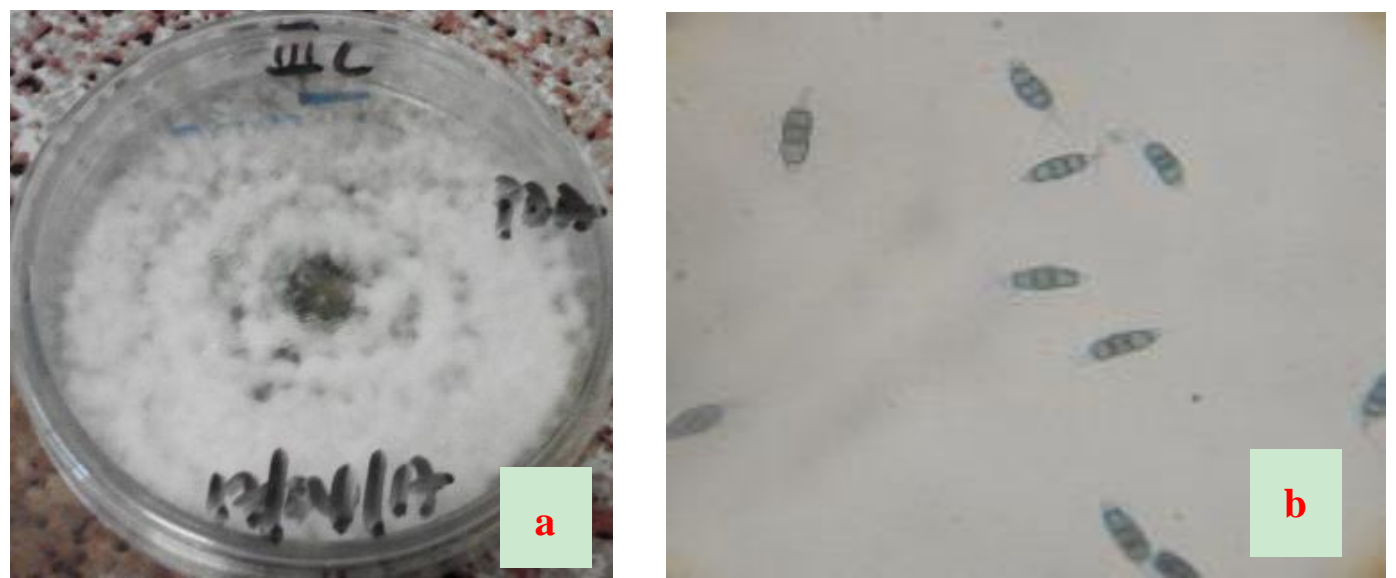

Figure 4. Morphology of sample III identified as Pestalotiopsis microspora: (a) Pure culture, (b) Spores

3.2 Phenotypic Description of the Fungi on PDA and PCDA in Petri Dishes with the Help of Mycroscopy

Characteristic features of the mycelia of each of the fungal strains were observed in Petri dishes. Table 2 gives the characteristics observed on the strains when they grew on PDA and 
PCDA culture media at ambient temperature of $25 \pm 2{ }^{\circ} \mathrm{C}$.

Table 2. Features observed for the fungal strains on culture media

\begin{tabular}{ccccl}
\hline \multirow{2}{*}{ Strain } & \multicolumn{3}{c}{ Feature } \\
\cline { 2 - 5 } & Form & Elevation & Margin & \multicolumn{1}{c}{ Colour } \\
\hline I & Circular & Raised & Entire & White all around and pinkish at center \\
\hline III & Circular & Raised & Entire & White (Snowish) \\
\hline
\end{tabular}

\subsection{Phenotypic Description of Features Observed Under the Microscope}

Table 3 gives a summary of the characteristics of hyphae and spores of the 3 fungi strains as observed under the microscope. Identification was done by comparing the hyphae and spores observed to those of already identified and documented fungi. The cultures "I" and "II" produced similar features (hyphae and spores) when observed under the microscope. They were identified as Fusarium oxysporum, while, culture "III" had features identical to those of Pestalotiopsis microspora.

Table 3. Features of fungal hyphae and spores as observed under the microscope

\begin{tabular}{cccl}
\hline \multirow{2}{*}{ Strain } & \multicolumn{2}{c}{ Features } \\
\cline { 2 - 4 } I & Septate and non-nucleited & Present & $\begin{array}{l}\text { Fusiform } \\
\text { and pointed at the tips, with 4-5 septa }\end{array}$ \\
\hline II & Septate and non-nucleited & Present & $\begin{array}{l}\text { Fusiform macroconidia, slightly curved } \\
\text { and pointed at the tips, with 4-5 septa }\end{array}$ \\
\hline III & & & $\begin{array}{l}\text { Fusiform, 5-celled, with three brown } \\
\text { median cells and hyaline end cells. Three } \\
\text { apical appendages arising from the apical } \\
\text { cell }\end{array}$ \\
& Aseptate & Present
\end{tabular}


3.4 Effect of Media on Mycelia Growth Rate of Fusarium oxysporum and Pestalotiopsis microspora

The various growth rates (mm/day) of the fungi on PDA and PCDA at room temperature $\left(25 \pm 2{ }^{\circ} \mathrm{C}\right)$ are recorded in table 4.

Table 4. Growth rate of fungi cultures on PDA and PCDA

\begin{tabular}{|c|c|c|}
\hline \multirow{2}{*}{ Strain } & \multicolumn{2}{|c|}{ Growth rate $\left(\mathrm{mm}^{-d a y^{-1}}\right)$} \\
\hline & PDA & PCDA \\
\hline F. oxysporum & 8.80 & 3.61 \\
\hline P. microspora & 6.28 & 1.11 \\
\hline
\end{tabular}

Figure 5 shows the number of days each fungus required to fill the $70 \mathrm{~mm}$ Petri dish. After culturing $F$. oxysporum and P. microspora on PDA and PCDA, both fungi were observed to grow faster on PDA than PCDA. F. oxysporum grew faster, filling the Petri dish at 6DAS (Days after subculture) while P. microspora filled the Petri dish at 8DAS (Fig 5). On PCDA, none of the fungi completed its growth even 12DAS. However, F. oxysporum attained a larger diameter $(4.6 \mathrm{~cm})$ than P. microspora $(2.6 \mathrm{~cm})$.

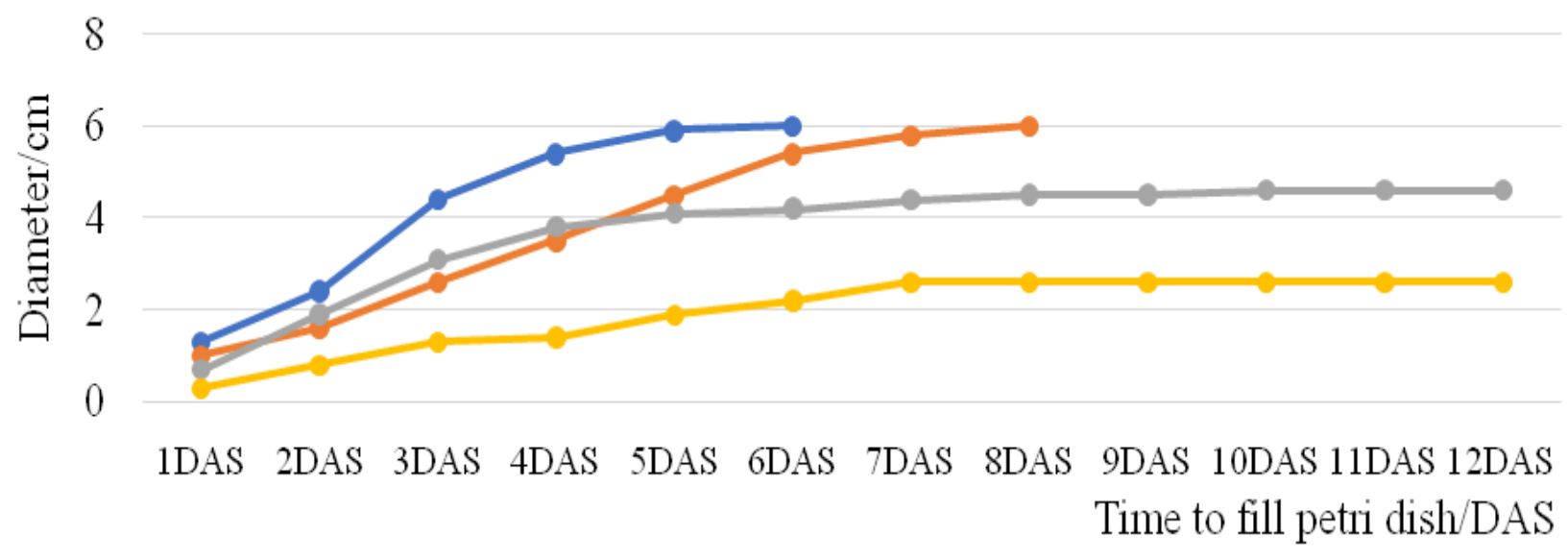

$\rightarrow$ PDA $F$. oxysporum $\rightarrow$ PDA $P$. microspora $\rightarrow$ PCDA $F$. oxysporum $\rightarrow$ PCDA $P$. microspora

Figure 5. Effect of PDA and PCDA culture media on the radial growth of $F$. oxysporum and $P$. microspora at $25 \pm 2{ }^{\circ} \mathrm{C}$

Both $F$. oxysporum and P. microspora grew best on PDA medium compared to PCDA medium, attaining their maximum growth at 6DAS and 8DAS respectively. Potato dextrose agar is a nutrient rich medium for growing a wide range of fungi (Hudec and Muchová, 2010). It is rich in nutritive elements necessary for the optimum growth of fungi such as 
carbohydrates (starch from potatoes) and dextrose which is a sugar that supplies energy to the fungi. PCDA on the contrary is made poorer by the addition of carrot into the medium. This is probably the reason why the fungi were not able to complete their growth.

\subsection{Effect of pH on Mycelial Growth Rate of F. oxysporum and P. microspora at $25 \pm 2{ }^{\circ} \mathrm{C}$}

Figure 6 shows the growth evolution of $F$. oxysporum and P. microspora on PDA and PCDA at $\mathrm{pH} \mathrm{5,} 7$ and 9. On PDA, F. oxysporum grew faster at $\mathrm{pH}$ 7, attaining its maximum diameter 5DAS, whereas still at 5DAS, P. microspora on PDA attained its maximum growth both at pH 5 and 7.

On PCDA, both F. oxysporum and P. microspora grew faster at $\mathrm{pH} 7$ attaining their maximum diameters at 5DAS.

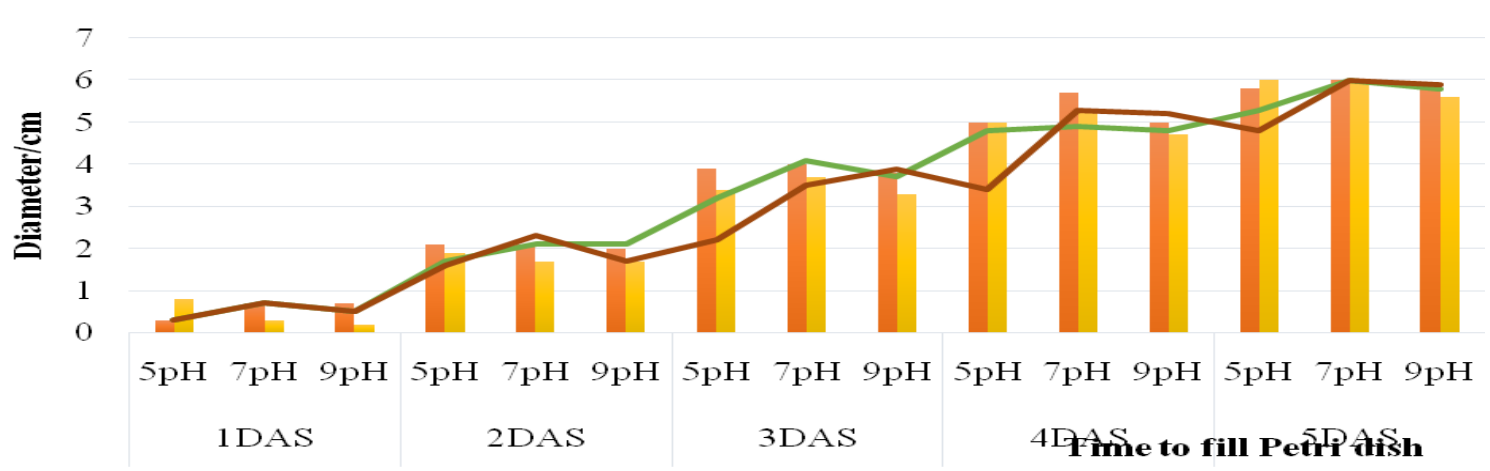

PDA F. oxysporum

PDA P. microspora

$\longrightarrow$ PCDA F. oxysporum $\longrightarrow$ PCDA P. microspora

Figure 6. Effect of $\mathrm{pH}$ on the radial growth of F. oxysporum and P. microspora

Both F. oxysporum and P. microspora grew best at a $\mathrm{pH}$ level of 7 . They grew best at neutral pH. Similar results were obtained by Joshi et al. (2013) in which $F$. oxysporum f. sp. solani grew best in slight alkaline conditions at $\mathrm{pH}$ 7.5. In a study by Srobar (1978), it was found that for mycelia of $F$. oxysporum which grew within the range of $\mathrm{pH} 2-12, \mathrm{pH} 0-6$ was the most suitable for the growth of all Fusarium species while a highly acidic medium was unsuitable for the sporulation of all Fusarium species. Azeez et al. (2016) observed highest mycelial biomass of Pestalotiopsis sp. at $\mathrm{pH} 9$ when studying its nutrient and physiological requirements for biomass production. The knowledge of the optimal fungal growth conditions is useful for future research endeavors.

\subsection{Effect of Temperature on the Radial Growth of F. oxysporum and P. microspora on PDA}

Overall, $25{ }^{\circ} \mathrm{C}$ was observed to be the most favourable temperature for both $F$. oxysporum and P. microspora. At this temperature, they both filled up the Petri dishes at 6DAS (Days after subculture). At $30{ }^{\circ} \mathrm{C}, F$. oxysporum took 10 days to attain maximum growth whereas the growth of $P$. microspora stopped at 5DAS where it reached a diameter of $4.8 \mathrm{~cm}$. At $35{ }^{\circ} \mathrm{C}$, no growth was observed neither for F. oxysporum nor for P. microspora.

Both $F$. oxysporum and $P$. microspora attained maximum radial diameter faster when 


\section{Macrothink Institute ${ }^{\text {TM }}$}

incubated at a temperature of $25^{\circ} \mathrm{C}$, at 5DAS and 6DAS respectively. This is in accordance with the results obtained by Hudec and Muchová (2010) where the mycelial growth of four Fusarium species was fastest at $25^{\circ} \mathrm{C}$. Azeez et al. (2016) obtained optimal mycelial growth of Pestalotiopsis sp. between $22^{\circ} \mathrm{C}$ and $28^{\circ} \mathrm{C}$. These could thus be considered as the appropriate temperature range for the culture of these fungi in research programmes.

\subsection{Application of Fungicides}

\subsubsection{Percent Inhibition of SF1 on Fusarium oxysporum and Pestalotiopsis microspora}

Synthetic fungicide 1 (SF1) was found to have a similar inhibitory effect on the growth of both $F$. oxysporum and P. microspora (Table 5), inhibiting their growth to $100 \%$ all through till 7DAS when the controls filled the Petri dishes.

Table 5. Percent inhibition of the growth of $F$. oxysporum by Synthetic fungicide 1 (SF1)

\begin{tabular}{|c|c|c|c|c|c|c|c|c|}
\hline \multirow{2}{*}{ Treatment } & \multirow{2}{*}{ Fungi } & \multicolumn{7}{|c|}{ Percent inhibition (\%) } \\
\hline & & 1 DAS & 2 DAS & 3 DAS & 4 DAS & 5 DAS & 6 DAS & 7 DAS \\
\hline \multirow[t]{2}{*}{ Control } & $\mathrm{F}$ & 93,5 & 79,4 & 67,5 & 43,1 & 23,7 & 9,5 & 0,7 \\
\hline & $\mathrm{P}$ & 94,7 & 75,3 & 47,0 & 25,7 & 7,9 & 1,2 & 1,2 \\
\hline \multirow[t]{2}{*}{0.005 g.L ${ }^{-1}$} & $\mathrm{~F}$ & 100,0 & 100,0 & 100,0 & 100,0 & 100,0 & 100,0 & 100,0 \\
\hline & $\mathrm{P}$ & 100,0 & 100,0 & 100,0 & 100,0 & 100,0 & 100,0 & 100,0 \\
\hline \multirow[t]{2}{*}{0.01 g. $L^{-1}$} & $\mathrm{~F}$ & 100,0 & 100,0 & 100,0 & 100,0 & 100,0 & 100,0 & 100,0 \\
\hline & $\mathrm{P}$ & 100,0 & 100,0 & 100,0 & 100,0 & 100,0 & 100,0 & 100,0 \\
\hline \multirow[t]{2}{*}{0.02 g. $L^{-1}$} & $\mathrm{~F}$ & 100,0 & 100,0 & 100,0 & 100,0 & 100,0 & 100,0 & 100,0 \\
\hline & $\mathrm{P}$ & 100,0 & 100,0 & 100,0 & 100,0 & 100,0 & 100,0 & 100,0 \\
\hline \multirow[t]{2}{*}{ CV \% } & $\mathrm{F}$ & 3,84 & 1,14 & 1,21 & 0,99 & 1,59 & 0,75 & 0,43 \\
\hline & $\mathrm{P}$ & 0,74 & 0,39 & 1,22 & 1,66 & 1,93 & 0,83 & 0,83 \\
\hline
\end{tabular}

Each value is the mean of three replications. $\mathrm{CV}=$ Coefficient of variation; $\mathrm{F}:$ Fusarium; $\mathrm{P}$ : Pestalotiopsis

Figure 8 below illustrates the growth of $F$. oxysporum on Synthetic fungicide 1 (SF1) amended culture medium (PDA) at various doses.
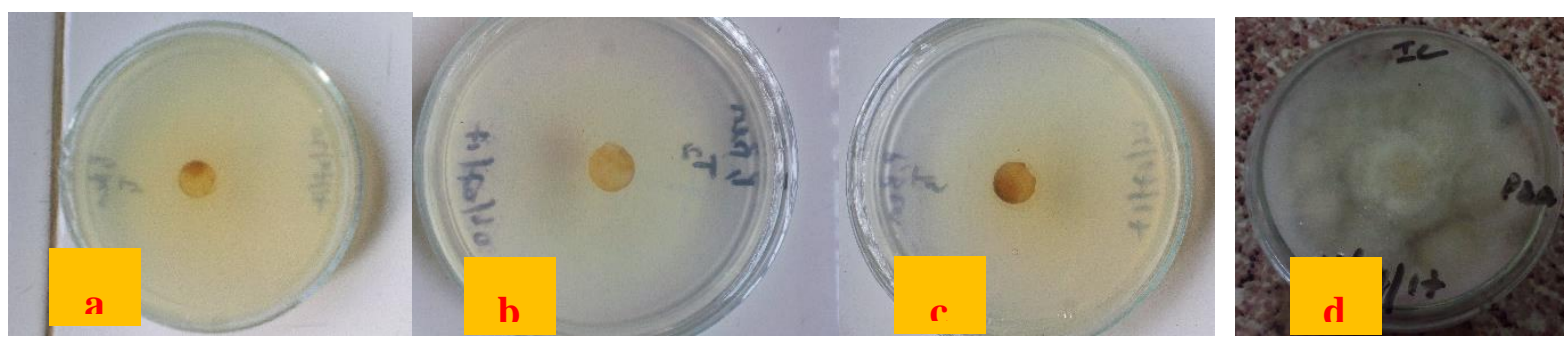

Figure 8. Growth of F. oxysporum on Synthetic fungicide 1 (SF1) amended PDA at (a) 0.005 g.L ${ }^{-1}$, (b) 0.01 g.L ${ }^{-1}$, (c) 0.02 g.L $\mathrm{L}^{-1}$, and (d) the control at 7DAS

Figure 9 below illustrates the growth of $P$. microspora on SF1 amended culture medium (PDA) at various doses. 


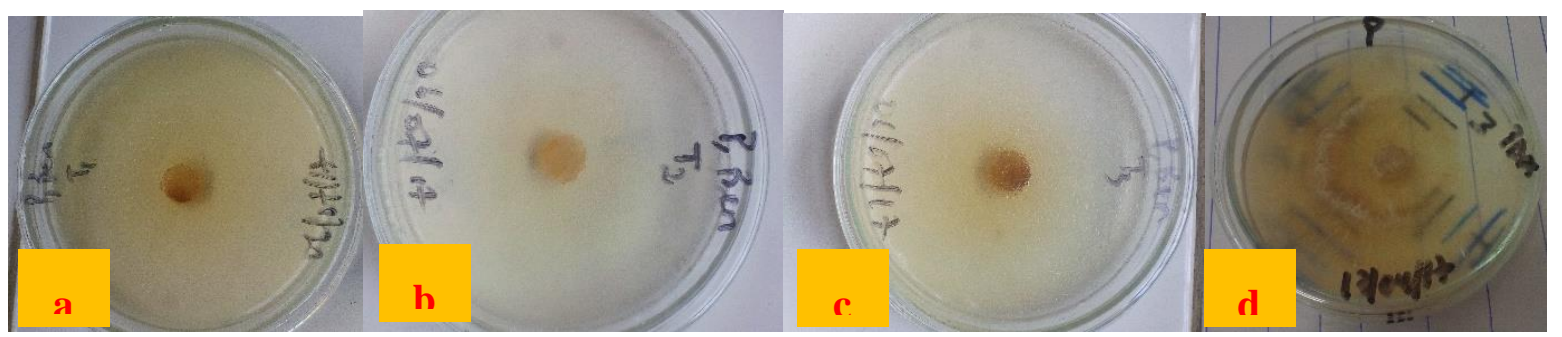

Figure 9. Growth of P. microspora on Synthetic fungicide 1 (SF1) amended PDA at (a) 0.005 g.L ${ }^{-1}$, (b) 0.01 g.L $L^{-1}$, (c) 0.02 g.L $L^{-1}$, and (d) the control at 7DAS

All three doses of the Synthetic fungicide 1 (SF1) with active ingredient Benlate 50 WP had a significant effect $(\mathrm{P}>0.05)$ on the growth of both $F$. oxysporum and P. microspora completely inhibiting $(100 \%)$ the growth of the fungi.

For Fusarium, this result is in accordance with the results obtained by Allen et al. (2004) and Iqbal (2010) who observed 100\% suppression of colony growth after testing the effect of SF1 on the growth of Fusarium species of longleaf pine and F. mangiferae respectively. Also, Amini and Sidovich (2010) and Wensley (1972) observed significant reductions in colony growth when used on F. oxysporum f. sp. lycopersici and Fusarium sp. causing fusarium wilt of muskmelon respectively.

For Pestalotiopsis, the result is in accordance with that obtained by Esiegbuya et al. (2014) who had $100 \%$ inhibition when Benlate at 500 ppm was used in vitro against $P$. clavispora. It is however contrary to what Panconesi et al. (1995) obtained when Benlate was tested against P. funerea, where it was found ineffective against the fungus.

Complete inhibition observed could be explained by the fact that SF1 belonging to the benzimidazole family is a systemic broad spectrum, protective and eradicant fungicide which is thought to act by inhibiting DNA synthesis. This therefore implies no synthesis of protein and other metabolites; hence the organism can no longer go through its normal physiological processes and so growth stops.

\subsubsection{Percent inhibition of SF2 on Fusarium oxysporum and Pestalotiopsis microspora}

Table 6 gives the percent inhibition of SF2 on the growth of $F$. oxysporum. At 1DAS, 3DAS, 6DAS, 7DAS and 8DAS, there was no statistical significant $(\mathrm{P}>0.05)$ inhibitory difference between the fungicide at all doses and the control. At 2DAS and 4DAS, 0.025 g.L ${ }^{-1}$ of the fungicide had the greatest inhibitory effect on the growth of the fungus. This was followed by the dose 0.013 g. $\mathrm{L}^{-1}$ while 0.006 g. $\mathrm{L}^{-1}$ had no significant $(\mathrm{P}>0.05)$ effect compared to the control. At 5DAS, there was a significant $(\mathrm{P}>0.05)$ difference between $0.025,0.013 \mathrm{~g} . \mathrm{L}^{-1}$ and the control; 0.013 g.L $\mathrm{L}^{-1}$ and 0.006 g.L $\mathrm{L}^{-1}$ were statistically similar while 0.006 g.L $\mathrm{L}^{-1}$ had no significant inhibitory effect compared to the control. Percent inhibition was observed to reduce with time (DAS). 


\section{Macrothink}

Table 6. Percent growth inhibition of $F$. oxysporum and $P$. microspora by SF2

\begin{tabular}{|c|c|c|c|c|c|c|c|c|c|}
\hline \multirow{2}{*}{ Treatments } & \multirow[t]{2}{*}{ Fungi } & \multicolumn{7}{|c|}{ Percent inhibition (\%) } & \multirow[b]{2}{*}{8 DAS } \\
\hline & & $1 \mathrm{DAS}$ & 2 DAS & 3 DAS & 4DAS & 5 DAS & 6 DAS & 7 DAS & \\
\hline Control & $\mathrm{F}$ & 93,5 & 79,4 & 67,5 & 43,1 & 23,7 & 9,5 & 0,7 & 0,0 \\
\hline & $\mathrm{P}$ & & & & & & & & \\
\hline 0.006 g.L $L^{-1}$ & $\mathrm{~F}$ & 99,7 & 81,1 & 62,6 & 43,7 & 26,3 & 11,0 & 5,7 & 4,5 \\
\hline 0.00 & $\mathrm{P}$ & 100,0 & 96,4 & 71 & 68,0 & 51,1 & 34,4 & 26,4 & \\
\hline 0.013 & $\mathrm{~F}$ & 100,0 & 84,6 & 65,2 & 49,8 & 33,1 & 15,6 & 7,3 & 7,0 \\
\hline 0.01 g.L $L^{-1}$ & $\mathrm{P}$ & 100,0 & 98,4 & 84,2 & 78,6 & 63,6 & 46,3 & 27,4 & \\
\hline 0.025 g.L $L^{-1}$ & $\mathrm{~F}$ & 100,0 & 91,0 & 65,6 & 56,7 & 39,5 & 20,5 & 8,5 & 5,1 \\
\hline 0.02 g.L $L^{-1}$ & $\mathrm{P}$ & 100 & 99,3 & 93,1 & 89,3 & 80,2 & 68,0 & 53,3 & \\
\hline CV \% & $\mathrm{F}$ & 2,62 & 1,80 & 3,14 & 4,45 & 12,16 & 37,23 & 114,07 & 159,44 \\
\hline & $\mathrm{P}$ & 0,74 & 0,92 & 5,22 & 6,31 & 9,04 & 15,30 & 50,99 & \\
\hline
\end{tabular}

Each value is the mean of three replications. $\mathrm{CV}=$ Coefficient of variation

Figure 10 illustrates the growth of $F$. oxysporum on SF2 amended culture medium (PDA) at various doses.

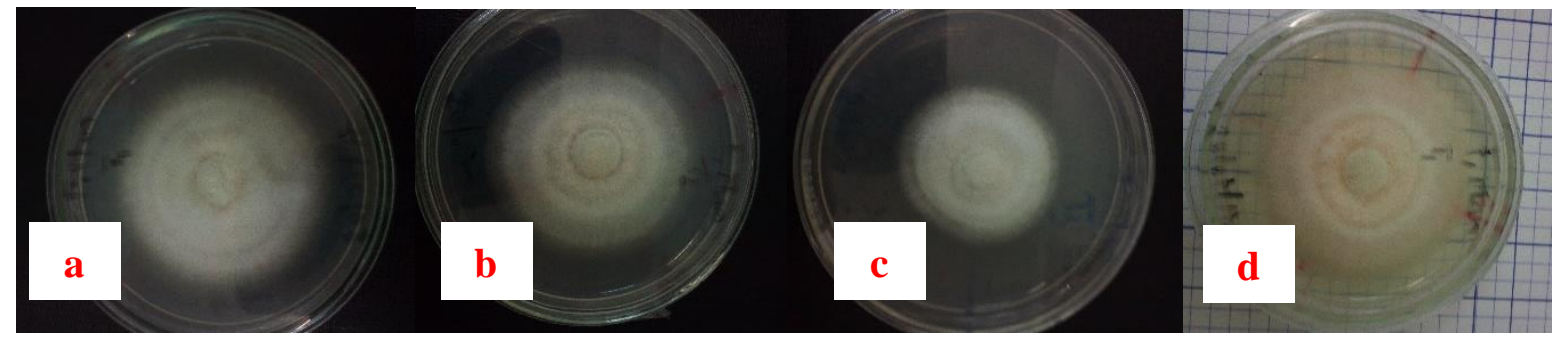

Figure 10. Growth of $F$. oxysporum on SF2 amended PDA at (a) 0.006 g.L $\mathrm{L}^{-1}$, (b) 0.013 g.L ${ }^{-1}$, (c) $0.025 \mathrm{~g} . \mathrm{L}^{-1}$, and (d) the control at 6DAS

Table 6 gives the percent inhibition of SF2 on the growth of P. microspora. Percent inhibition reduced with time (DAS). 0.02 g. $\mathrm{L}^{-1}$ had the greatest inhibitory effect on the growth of the

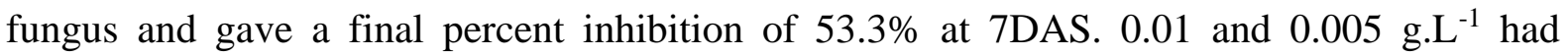
statistically similar inhibitory effects compared to the control though they were equally significantly $(\mathrm{P}>0.05)$ similar to $0.02 \mathrm{~g} . \mathrm{L}^{-1}$ at $7 \mathrm{DAS}$.

Figure 11 illustrates the growth of $P$. microspora on SF2 amended culture medium (PDA) at various doses.

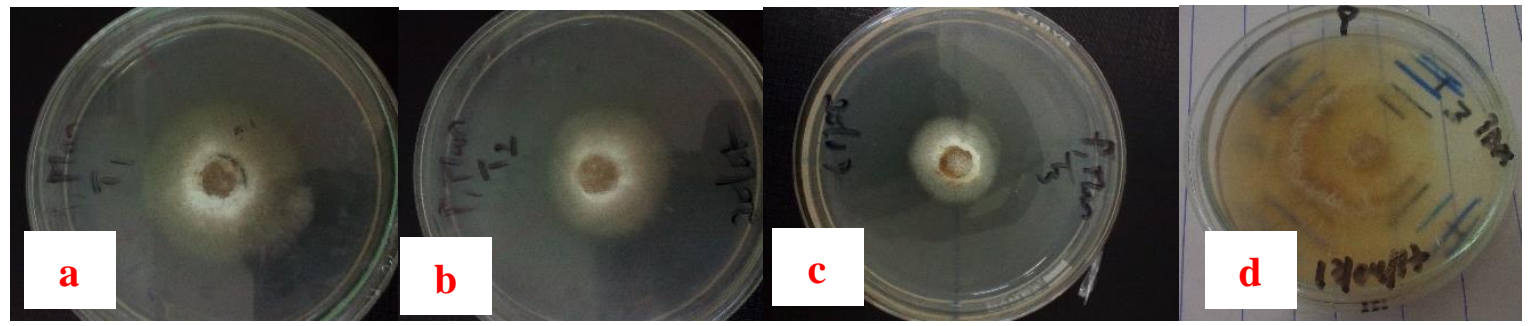

Figure 11. Growth of P. microspora on SF2 amended PDA at (a) 0.006 g. $\mathrm{L}^{-1}$, (b) 0.013 g.L ${ }^{1}$, (c) $0.025 \mathrm{~g} . \mathrm{L}^{-1}$, and (d) the control at 5DAS 
The SF2 (Pencozeb 80WP) at all doses had varying inhibitory effects on both fungi. $P$. microspora was more sensitive to the fungicide than $F$. oxysporum. The dose $0.025 \mathrm{~g} . \mathrm{L}^{-1}$ was found most effective against $P$. microspora where it resulted in $53.3 \%$ inhibition of the growth of this fungus. SF2 did not have a great inhibitory effect on the growth of $F$. oxysporum, giving a percent inhibition of $7 \%$ at the dose of $0.013 \mathrm{~g} . \mathrm{L}^{-1}$ at $8 \mathrm{DAS}$. This was not significantly $(\mathrm{P}>0.05)$ different from the control. Though $0.025 \mathrm{~g} . \mathrm{L}^{-1}$ inhibited the growth of $F$. oxysporum most from 1DAS to 7DAS, the dose 0.013 g. $\mathrm{L}^{-1}$ finally gave a greater percent inhibition at $8 \mathrm{DAS}$. The rate of fungal growth increased with longer duration of treatment.

For F. oxysporum, when Maitlo et al. (2014) used Dithane-M in combination with metalaxil against fusarium wilt of chickpea caused by F. oxysporum f. sp. cubense, it was found not to be efficient against the fungus at any dose. Kumari et al. (2014) obtained significant reductions in mycelial growth of Fusarium oxysporum f. sp. cubense in vitro. Andrabi et al. (2011) obtained $56.66 \%$ and $70.94 \%$ inhibition for F. oxysporum and F. solani respectively when SF2 was used to control various wilt-causing pathogens in chickpea. Allen et al. (2004) observed complete inhibition of the growth of four Fusarium species associated with longleaf pine seeds.

For P. microspora, similar results were obtained by Kumhar et al. (2016) where maximum inhibition of $70.8 \%$ was observed when SF2 was used as a means to control $P$. theae causing grey blight in tea. Ray et al. (2016) obtained complete inhibition of fungal growth when SF2 (0.02\%) was used in vitro to control $P$. disseminata causing grey blight disease in Persea bombycina.

SF2 is a contact, non-systemic fungicide that inhibits the formation of germ tube of fungal species. Its mode of action is less effective against fungi than that of systemic fungicides like $\mathrm{SF} 1$. This could be a possible reason why in the present study, when both fungi (especially $F$. oxysporum) were grown on SF2-amended PDA, the mycelial growth was first slow on the first days and then began growing faster with time, hence a very low percent inhibition $(F$. oxysporum). F. oxysporum was less sensitive to SF2 than $P$. microspora probably because it must have quickly developed mechanisms to resist the action of the fungicide given that it is a contact fungicide.

Also, SF2 is a broad-spectrum fungicide that has been used for several years (since 1948; USAID, 2012) to control a number of fungi among which are $F$. oxysporum and $P$. microspora. The low sensitivity of $F$. oxysporum observed in the present study could be associated to the hypothesis that this fungus might have developed resistance to this particular fungicide, reason why the percent inhibition obtained was very low even at the highest recommended dose of the product.

\subsection{Pathogenicity Test}

Two days after inoculation of fungi spores on detached leaves at room temperature $\left(25 \pm 2{ }^{\circ} \mathrm{C}\right)$, the following symptoms were observed: 


\section{Fusarium oxysporum}

Symptoms started as dark spots on the surface of the leaves. They first started on the sites where the spore suspension was placed, then spread to other parts of the leaf. Leaf edges and tips wilted, becoming brownish and then yellowish. These later on progressed from the tips towards the center of the leaf. Symptoms were similar to those observed on the leaves from which the fungus had been initially isolated.

\section{Pestalotiopsis microspora}

Symptoms appeared as dark spots on the sites where the spores had been inoculated. Spots turned grey at the center while the surroundings became yellowish. Spots spread to other parts of the leaf surface and later on coalesced to a dark necrotic tissue plaque, leading to yellowing of leaves around the plaque.

\section{Conclusion}

This study was carried out in order to determine the effect of two fungicides; synthetic fungicide 1 (SF1) and synthetic fungicide 2 (SF2) on the radial growth of Fusarium oxysporum and Pestalotiopsis microspora, which are fungi associated with the leaf blight of rubber (Hevea brasiliensis Muell Arg.). In order to achieve this, characterizing the fungi was an indispensable step. This was done by evaluating the best culture medium and the most suitable $\mathrm{pH}$ and temperature for the growth of the fungi. From the results obtained, it can be noted that Potato Dextrose Agar (PDA) culture medium is best suited for the growth of both $F$. oxysporum and $P$. microspora especially when adjusted to $\mathrm{pH} 7$ and incubated at a temperature of $25{ }^{\circ} \mathrm{C}$. Result also showed that without variations in temperature, both fungi could as well grow on PCDA if its $\mathrm{pH}$ was adjusted to 7 . When spores of both $F$. oxysporum and $P$. microspora were inoculated on detached leaves in vitro, similar symptoms as those observed on the field were obtained, demonstrating that these fungi were responsible for blight and wilt disease respectively occurring on the leaves of the rubber plant. Comparing both fungicides used against the fungi, SF1 (a systemic fungicide) was found to be most effective, completely inhibiting the growth of both $F$. oxysporum and $P$. microspora at all doses. SF2 (a contact fungicide) was more effective against $P$. microspora than $F$. oxysporum. It was found to be most effective at the dose 0.025 g.L ${ }^{-1}$.

The results of this study suggest that in order to have an optimum growth of Fusarium oxysporum and Pestalotiopsis microspora in vitro, they should both be cultured on PDA at $\mathrm{pH} 7$ and incubated at a temperature of $25^{\circ} \mathrm{C}$. Moreover,control of blight and wilt diseases caused by these fungi on the leaves of the rubber plant could be done using the chemical method, by applying SF1 and SF2 at reasonable doses.

\section{References}

Allen, T. W., Enebak, S. A., \& Carey, W. A. (2004). Evaluation of Fungicides for control of species of Fusarium on Longleaf Pine Seed. Crop Protection, 23, 979-982. https://doi.org/10.1016/j.cropro.2004.02.010

Amin, A. A. (2002). An examination of the Sources of Economic Growth in Cameroon. 
African Economic Research Consortium, Nairobi. AERC Research Paper 116.

Amini, J., \& Sidovich, D. (2010). The Effects of Fungicides on Fusarium oxysporum f. sp. lycopersicy associated with fusarium wilt of tomato. Journal of Plant Protection Research, 50(2), 172-178. https://doi.org/10.2478/v10045-010-0029-x

Dhingra, O. D., \& Sinclair, J. B. (1985). Basic Plant Pathology Methods. CRC Press, Florida. P 325.

Djeugap, J. (2013). Contraintes de germination et diagnostic moléculaire des champignons associés aux maladies chez Ricinodendronheudelotii au Cameroun.158 p.

Gazis, \& Chaverri, (2010). Diversity of fungal endophytes in leaves and stems of wild rubber trees (Hevea brasiliensis) in Peru. Fungal Ecology, 3(3), 240-254. https://doi.org/10.1016/j.funeco.2009.12.001

Hudec, K., \& Muchová, D. (2010). Influence of Temperature and Species Origin on Fusarium spp. and Microdochiumnivale pathogenicity to wheat seedlings. Plant Protection Science, 46, 59-65. https://doi.org/10.17221/12/2009-PPS

Iqbal, Z., Pervez, M. A., Salman, A., Yasir, I., Yasin, M., Nawaz, A., ... Ahmad, S. (2010). Determination of Minimum Inhibitory Concentrations of Fungicides Against Fusarium mangiferae. Pakistan Journal of Botany, 42(5), 3525-3532.

Joshi, M., Rashmi, S., Sharma, A. K., \& Anil, P. (2013). Isolation and Characterization of Fusarium oxysporum, a Wilt Causing Fungus, for its Pathogenic and Non-pathogenic Nature in Tomato (Solanum lycopersicum). Journal of Applied and Natural Science, 5(1), 108-117. https://doi.org/10.31018/jans.v5i1.290

Kumari, A., Rahul, K., \& Harsh, K. (2014). Efficacy of Fungicides and Trichoderma viridaeagainst Fusarium oxyporum f. sp.cubense in vitro. The bioscan, 9(3), 1355-1358.

Maitlo, S. A., Syed, R. N., Rustamani, M. A., Khuhro, R. D., \& Lodhi, A. M. (2014). Comparative Efficacy of Different Fungicides Against Fusarium Wilt of Chickpea (Cicer Arietinum L.). Pakistan Journal of Botany, 46(6), 2305-2312.

Martins, M. B. G., \& Zieri, R. (2003). Leaf Anatomy of Rubber-tree Clones. Scientia Agricola, 60(4), 709-713. https://doi.org/10.1590/S0103-90162003000400015

Naz, F., Rauf, C. A., Haque, I. U., \& Ahmad, I. (2006). Management of Rhizoctonia solani with Plant Diffusates and Chemicals. Pakistan Journal of Phytopathology, 18(1), 36-43.

Nyaka Ngobisa, A. I. C., Owona, N. P. A, Doungous, O., Ntsomboh-Ntsefong, G., Njonje, S. W., \& Ehabe, E. E. (2018). Characterization of Pestalotiopsis micospora, the causal agent of rubber leaf blight disease in Cameroon. Rubber Science, 31(2), 112-120.

Ray, M. K., Mishra, P. K., \& Baruah, P. K. (2016). Control of Fungal Pathogen Pestalotiopsis disseminate Causing Grey Blight Disease in Som (Persea bombycina Kost.): An In Vitro Study. International Journal of Pureand Applied Bioscience, 4(6), 180-185. https://doi.org/10.18782/2320-7051.2412 
Reinhard, L. (2007). South American Leaf Blight of the Rubber Tree (Hevea spp.): New Steps in Plant Domestication using Physiological Features and Molecular Markers. Annals of Botany, 100, 1125-1142. https://doi.org/10.1093/aob/mcm133

Safwan, M. Noraini, M.J. Aswad, W. Zulkefly, S. Heraa, R., \& Dzarifah, Z. (2019). Major Diseases of Rubber (Hevea brasiliensis) in Malaysia. Pertanika Journal of Scholarly Research Reviews, 5(2), 10-21. http://www.pjsrr.upm.edu.my/

Sanjay R., (2004). Studies on Pestalotiopsis spp affecting tea (Camelliasiensis (L) O Kuntze in southern India. PhD thesis, Bharathiar University, Coimbatore.

Srobar, S. (1978). The Influence of Temperature and pH on the Growth of Mycelium of the Causative Agents of Fusarioses in the Wheat in Slovakia Czechoslovakia. Sbornik- Ustav Vedeckotechnickych-Informaci-Ochrana-Rostlin, 14, 269-274.

UIA (2000). Pests and Diseases of Rubber. The Encyclopedia of World Problems and Human Potential. www.uia.org

USAID (2012). Agrochemical General Information Sheet - Mancozeb. Technical Bulletin \#53

Venkatachalam, P., Geetha, N., Sangeetha, P., \& Thulaseedharan, A. (2013). Natural Rubber Producing Plants: An Overview. African Journal of Biotechnology, 12(12), 1297-1310. Available online at http://www.academicjournals.org/AJB

Verheye, W. (2010). Growth and Production of Rubber. In: Verheye, W. (ed.), Land Use, Land Cover and Soil Sciences. Encyclopedia of Life Support Systems (EOLSS), UNESCO-EOLSS Publishers, Oxford, UK. http://www.eolss.net.

Wensley, R. N. (1972). Effects of Benomyl and Two Related Fungicides on Growth of Fusarium Wilt-susceptible and Resistant Muskmelon. Canadian Journal of Plant Sciences, 52, 775-779. https://doi.org/10.4141/cjps72-126

\section{Copyright Disclaimer}

Copyright for this article is retained by the author(s), with first publication rights granted to the journal.

This is an open-access article distributed under the terms and conditions of the Creative Commons Attribution license (http://creativecommons.org/licenses/by/4.0/). 